7. Reprod. Fert. (1970) 21, 179-181

\title{
THE CHARACTERIZATION OF GLUCOSE-6-PHOSPHATE DEHYDROGENASE IN MOUSE OVA
}

\author{
C. J. EPSTEIN, G. W. SMITH AND LILLIAN W. KWOK \\ Department of Pediatrics, University of California \\ San Francisco Medical Center, San Francisco, California
}

(Received 21st fuly 1969)

Previous studies have indicated that the glucose-6-phosphate dehydrogenase (G6PD) contained within mouse ova is synthesized before ovulation and is under the genetic control of the X-chromosome (Epstein, Wegienka \& Smith, 1969; Epstein, 1969). As such, it is different from the autosomally controlled hexose-6-phosphate dehydrogenase (H6PD) or glucose dehydrogenase found in liver microsomes but not in erythrocytes (Beutler \& Morrison, 1967). To establish the applicability of these genetic results with ova to other tissues of the mouse, G6PD from ova has been characterized and compared with erythrocyte G6PD.

Ova and pre-implantation embryos were obtained from Swiss albino mice (Mus musculus) by superovulation. For microspectrophotometric assay of enzyme activity, they were lysed by freezing and thawing in $0.05 \mathrm{M}$-tris buffer, pH 7.5, containing $0.05 \%$ bovine serum albumin (BSA) (Epstein et al., 1969). For polyacrylamide disc gel electrophoretic studies, the ova and embryos were lysed in upper gel buffer containing $10^{-5} \mathrm{M}-\mathrm{NADP}$ and $0.1 \% \mathrm{BSA}$ (Kirkman \& Hanna, 1968). Erythrocytes obtained from the same animals were lysed by freezing and thawing in the same solutions. Hexose-6-phosphate dehydrogenase was prepared from isolated liver microsomes by extraction with $0.5 \%$ sodium cholate (Beutler \& Morrison, 1967). G6PD and H6PD activities in erythrocytes and liver were determined by a micromodification of the procedure of Glock \& McLean (1953) in which correction is made for 6-phosphogluconate dehydrogenase activity (Epstein et al., 1969). No such correction is required for egg G6PD, since the latter enzyme is not measurable in these cells.

Enzyme activity was measured as a function of substrate concentration, and the results are shown in Text-fig. 1. When erythrocyte and egg G6PD were adjusted to the same initial activity with $0.45 \mathrm{~mm}$-substrate, both enzymes gave the identical line in the plot of $\mathrm{S} / \mathrm{V}$ versus $\mathrm{S}$, where $\mathrm{S}$ represents substrate concentration and $V$ represents reaction velocity. The Michaelis constant, $K_{m}$, for the enzymes from both sources is calculated to be $42.3 \mu \mathrm{M}$, a value not too dissimilar from the $\mathrm{K}_{\mathrm{m}}$ of $49 \pm 4 \mu \mathrm{M}$ reported for human G6PD-B (Dern, McCurdy \& Yoshida, 1969).

On polyacrylamide disc gel electrophoresis (Plate 1), G6PD from ova migrates toward the anode as a single major band. Fifty ova were used for each sample. Erythrocyte G6PD migrates as a rapidly moving major band and one 
or two less rapid minor bands, but the major band of erythrocyte G6PD and the single band of egg G6PD have identical electrophoretic mobilities.

The activities of G6PD from ova and erythrocytes and of H6PD from liver

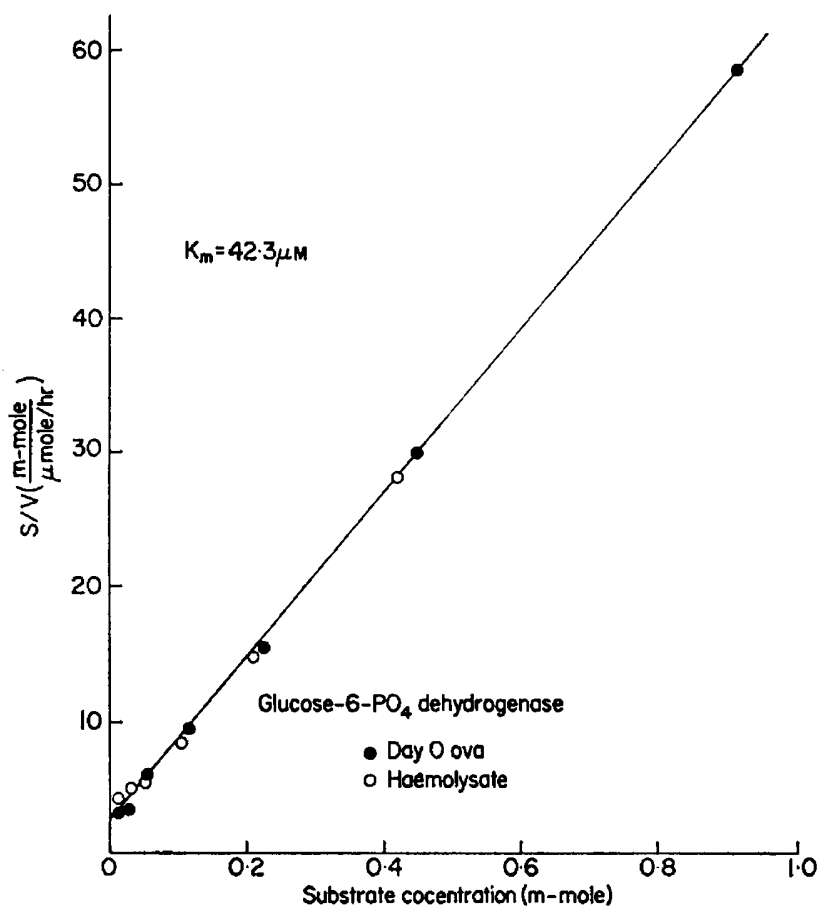

TeXT-Fig. 1. Plot of $S / V$ versus $S$ for mouse erythrocyte and ova G6PD. S represents substrate concentration, and $V$ represents rate of reaction at $37^{\circ} \mathrm{C}$.

TABLE 1

AGTIVITY OF ENZYME PREPARATIONS WITH G6P AND GAL-6-P*

\begin{tabular}{|c|c|c|c|}
\hline Source of enzyme & \multicolumn{2}{|c|}{ 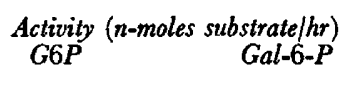 } & $\begin{array}{c}\text { Ratio of activities } \\
\text { Gal-6-P, } \\
G 6 P\end{array}$ \\
\hline $\begin{array}{l}\text { Mouse ova } \\
\text { Erythrocytes } \\
\text { Microsomes (liver) }\end{array}$ & $\begin{array}{l}1 \cdot 64 \\
22 \cdot 2^{\dagger} \dagger \\
3 \cdot 21 \dagger\end{array}$ & $\begin{array}{l}0 \cdot 23 \\
5 \cdot 83 \\
3 \cdot 71\end{array}$ & $\begin{array}{l}0.14 \\
0.17 \\
1 \cdot 15\end{array}$ \\
\hline
\end{tabular}

* Activity expressed per embryo for ova assays, per arbitrary aliquot for erythrocyte and microsome assays. Substrate concentration, $1.0 \mathrm{~mm}$.

t Corrected for 6-phosphogluconate dehydrogenase.

microsomes were determined with equimolar concentrations of glucose-6-phosphate (G6P) and galactose-6-phosphate (Gal-6-P) as substrates, and the results are shown in Table 1 . The ratios of activity with Gal-6-P to activity with G6P are the same, $0 \cdot 14$ to $0 \cdot 17$, for the erythrocyte and egg enzymes, and these ratios differ quite markedly from that of 1.15 observed for microsomal H6PD. 
PLATE 1

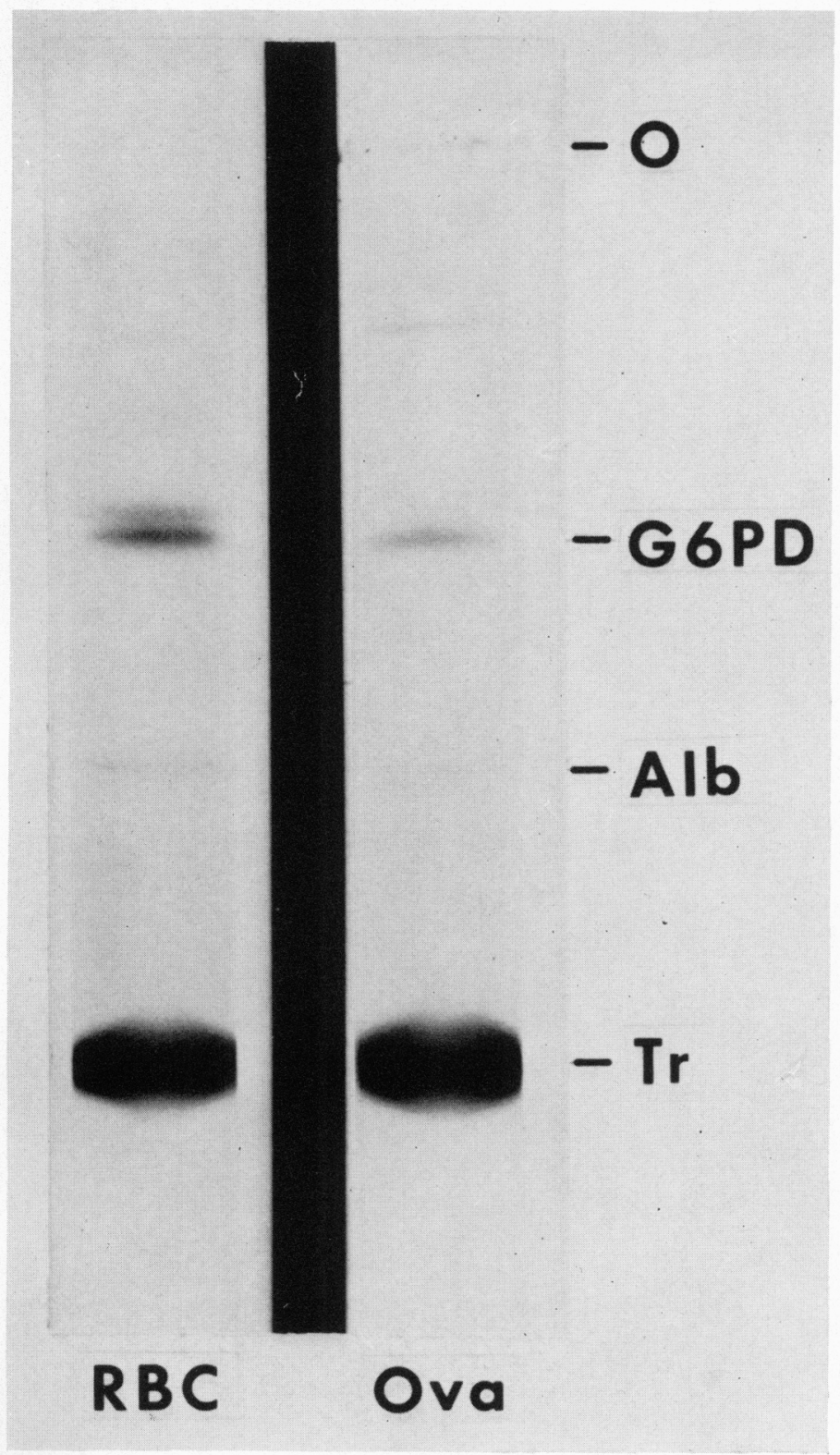

Electrophoretic pattern of erythrocyte (RBC) and ova G6PD in polyacrylamide gels, $7.5 \%$, pH 8.6, with $10^{-5} \mathrm{M}-\mathrm{NADP}$ in buffers (Kirkman \& Hanna, 1968). The gels were stained with nitro BT tetrazolium, using $6 \times 10^{-2} \mathrm{M}-\mathrm{G} 6 \mathrm{P}$ as substrate (Wajntal \& DeMars, 1967). O, origin; Alb, albumin with bound tracker dye; Tr, tracker dye. Anode at bottom. 
In other species, including man, hare and horse, the synthesis and structure of erythrocyte G6PD is controlled by the X-chromosome (Ohno, 1967). Direct evidence utilizing variant forms of G6PD has not been obtained for the mouse, but, as has already been mentioned, genetic evidence indicates that the G6PD present in ova and pre-implantation embryos is X-linked. On the basis of $\mathrm{K}_{\mathrm{m}}$, electrophoretic mobility, and substrate specificity, mouse erythrocyte and egg G6PD appear to be the same enzyme. It is concluded, therefore, that mouse erythrocyte G6PD, like that of the other species, is X-linked.

This work was supported by grants from the NICHD, National Institutes of Health (USPHS) and the University of California School of Medicine, San Francisco, and by a Research Career Development Award from the NICHD, NIH.

\section{REFERENCES}

Beurler, E. \& Morrison, M. (1967) Localization and characteristics of hexose-6-phosphate dehydrogenase (glucose dehydrogenase). F. biol. Chem. 242, 5289.

Dern, R. J., MCCuRdy, P. R. \& YoshidA, A. (1969) A new structural variant of glucose-6-phosphate dehydrogenase with a high production rate (G6PD Hektoen). 7. Lab. clin. Med. 73, 283.

Epstein, C. J. (1969) Mammalian oocytes: $\mathrm{X}$ chromosome activity. Science, N.Y. 163, 1078.

Epstein, G. J., WegrenKa, E. A. \& SмTTH, C. W. (1969) Biochemical development of preimplantation mouse embryos: in vivo activities of fructose 1,6-diphosphate aldolase, glucose-6-phosphate dehydrogenase, malate dehydrogenase, and lactate dehydrogenase. Biochem. Genetics, 3, 271.

GLOCK, G. E. \& McLean, P. (1953) Further studies on the properties and assay of glucose-6-phosphate dehydrogenase and 6-phosphogluconate dehydrogenase of rat liver. Biochem. F. 55, 400.

KiRkMan, H. N. \& Hanna, J. E. (1968) Isozymes of human red cell glucose-6-phosphate dehydrogenase. Ann. N.Y. Acad. Sci. 151, 133.

Ohno, S. (1967) Sex chromosomes and sex-linked genes. Springer, Berlin.

WajNTAL, A. \& DEMARs, R. (1967) A tetrazolium method for distinguishing between cultured human fibroblasts having either normal or deficient levels of glucose-6-phosphate dehydrogenase. Biochem. Genetics, 1, 61 . 